\title{
A articulação de três tempos para a construção de um espaço de escuta: teatro com jovens em situação de cárcere
}

Caroline Vetori de Souza ${ }^{1}$

Recebido em: 11/09/2019

Aprovado em: 30/10/2019

DOI: $10.5965 / 2358092521222019101$

${ }^{1}$ Licenciada em Teatro pela UFRGS. Mestranda em Teatro pela UDESC, atriz, escritora e professora de Teatro. E-mail: vetoricaroline@gmail.com 


\section{RESUMO}

No presente artigo, compartilha-se o trabalho desenvolvido com jovens em situação de cárcere, que cumpriam medida socioeducativa no Centro de Atendimento Socioeducativo Feminino (CASEF), da Fundação de Atendimento Socioeducativo do Rio Grande do Sul. Ao buscar trabalhar com o passado das jovens, através da prática, compreendeu-se a potência do trabalho com as noções de presente e futuro, somando-se à de passado, na construção de espaços necessários de escuta.

Palavras-chave: Teatro; Pedagogia; Jovens; Cárcere.

\section{ABSTRACT}

In this article it is shared the work developed with young people in prison, serving socio-educational measures in the Centro de Atendimento Socioeducativo Feminino (CASEF), of the Fundação de Atendimento Socioeducativo do Rio Grande do Sul. While aiming to work throughout the past of the young prisoners, by means of practical work, understanding was developed about the potential of practical work and the notions of present and future, as well as conceptions of past, in the construction of necessary listening spaces.

Keywords: Theater; Pedagogy; Young prisoners; Prison.

\section{AUSCULTANDO O ESPAÇO}

No presente artigo compartilho o breve processo teatral que desenvolvi junto à jovens que cumpriam medida socioeducativa no Centro de Atendimento Socioeducativo Feminino (CASEF). Em meu trabalho de conclusão de curso, da Licenciatura em Teatro, intitulado Teatro com jovens em situação de cárcere: $a$ 
construção de um espaço de escuta, sob orientação da profa. Dra. Vera Bertoni e co-orientação do doutorando Davi Giordano, feito na UFRGS, compartilho minha atuação, de cunho voluntário, na referida instituição.

O trabalho se deu no segundo semestre de 2017, dentro do CASEF. O CASEF surgiu na década de 60, então Lar Santa Marta ${ }^{2}$. Faz-se pertinente atentar que é a única unidade para atendimento feminino de menores de 18 anos no Estado do Rio Grande do Sul. Desta forma, as jovens podem vir de diferentes regiões, estando, por vezes, distantes de suas famílias, levando a um quadro de pouca visitação.

O CASEF está situado na Vila Cruzeiro, do município de Porto Alegre (RS), em um complexo onde abrigam outras unidades da Fundação de Atendimento Socioeducativo do Rio Grande do Sul (FASE). Para chegar ao local, saindo da região central da cidade, a linha de ônibus disponível é a 149 Icaraí. Desce-se na esquina da Rua Jaguari e há uma pequena quadra até o portão da instituição. Durante minhas idas ao local, houve um período que a rota fora alterada em decorrência do desabamento de um trecho de asfalto. Assim, descia algumas quadras mais longe e pude notar que o trecho mais precarizado era o próximo à instituição, com lixos jogados na rua e vazamentos de água.

O CASEF tem capacidade para 33 jovens, destinado apenas às jovens do sexo feminino que, segundo consta no próprio site da Fundação (2017) "cumprem medida de Semiliberdade, Internação com Possibilidade de Atividade Externa (ICPAE), Internação sem Possibilidade de Atividade Externa (ISPAE) e Internação Provisória"3.

2 Em A "casa de bonecas": um estudo de caso sobre a unidade de atendimento socioeducativo feminino no RS, a socióloga Rochelle Fachinetto traça um panorama histórico da casa. 


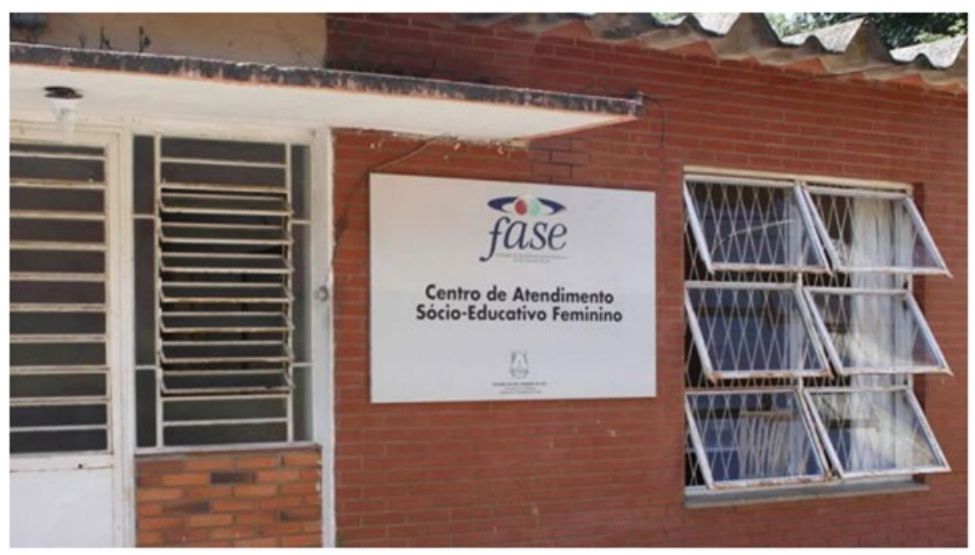

Figura 1: fachada do CASEF.

Fonte: site da instituição ${ }^{4}$

As medidas socioeducativas estão previstas no Estatuto da Criança e do Adolescente (ECA) ${ }^{5}$, no artigo 112, tendo diversas características. Há, dentre elas, a medida socioeducativa de internação, que era o caso das jovens com as quais trabalhei, especificamente, jovens em medida de internação sem possibilidade de atividade externa (ISPAE) ${ }^{6}$.

Os encontros de teatro aconteceram uma vez por semana, contando com apenas uma hora de duração, entre $21 \mathrm{~h}$ e $22 \mathrm{~h}$, pois era o período designado pela coordenação do local. Importante apontar o horário, pois as jovens já haviam passado por um dia repleto de atividades, chegando cansadas na oficina.

Uma das características das medidas socioeducativas é a brevidade, sendo, então, intensa a rotatividade das jovens na

4 Ibidem.

5 Lei $n^{\circ} 8.069 / 90$.

6 No CASEF as duas formas mais comuns de internação são: Internação com possibilidade de atividade externa (ICPAE) e Internação sem possibilidade de atividade externa (ISPAE). 
atividade. Isso se apresentou como um desafio: como desenvolver um trabalho de caráter continuado, sendo que me deparava constantemente com rostos novos e sentia a ausência de tantos outros? O laço coletivo, o trabalho de grupo é uma das características centrais do fazer teatral. Mas como criar esse senso de coletivo se nunca éramos o mesmo grupo? Precisei redimensionar meu olhar, fomentando um trabalho voltando ao espaço, ou seja, lutando pelo espaço para o trabalho teatral, através de uma prática constante, a se instalar nas atividades do centro.

Em muitas semanas não conseguia dar aula, por motivos diversos, seja em decorrência de colisões com outros eventos, como o evento mensal, de cunho cultural, no qual traziam artistas para compartilhar seu trabalho com as meninas, ou por baixo efetivo de funcionários. Aponto para essa questão porque quebrava a continuidade da prática, sendo necessárias estratégias para mobilizar as estudantes, e também para compartilhar com outras docentes sobre o percurso que, por vezes, conta com atravessamentos de outra ordem. Gostaria de pontuar que não há uma crítica implícita, porque compreendo a importância dos eventos, bem como respeito o contexto e suas complexidades.

No início, a pedido da coordenação, trabalhei com dois grupos, decorrentes da divisão relativa às alas nas quais as jovens estavam alocadas, buscando contemplar o maior número de jovens, trabalhando alternadamente a cada semana com um cada grupo. Somava-se mais complexidade ao trabalho, pois, além da rotatividade das participantes, veria cada grupo a cada duas semanas, sendo mais dispendioso retomar o que fora trabalhado no encontro precedente. Depois de um tempo de experimentação, em diálogo com a coordenação pedagógica da instituição, dado essa complexidade, transformou-se a logística da oficina, passando para o trabalho somente com um grupo.

Em nossos primeiros encontros propus jogos de aproximação, buscando instaurar um ambiente de trabalho confortável. Atento para o jogo no qual cada uma dizia seu nome seguido de algum movimento a partir de alguma qualidade - por exemplo: "Carol alegre" (o que correspondia a um movimento livremente criado inspirada nessa qualidade), e, logo em seguida, todas re- 
petiam. Apesar de extremamente simples, a proposta teve uma reverberação interessante, pois era visível a leveza das meninas ao poder se expor em relação a alguma qualidade, algo que, talvez, não seja tão enfatizado na instituição. Nas semanas seguintes, encontrava várias meninas que me viam e faziam os gestos criados com um sorriso no rosto.

Também propus, em nossas primeiras aulas, momentos de sensibilização, buscando que elas percebessem o espaço de outra maneira, bem como a si mesmas. Um dos exercícios feitos dava-se em duplas, uma ao lado da outra, tocando apenas ombro no ombro, uma com os olhos fechados e a outra com os olhos abertos que, então, conduziria apenas através dessa conexão corporal sutil, sem uso de palavras. Entre risos, as meninas brincavam, talvez, redescobrindo aquele espaço, ocupando-o de outras maneiras.

Planejava aulas semelhantes para os grupos, mas em decorrência das características de cada um, havia muitas diferenças. Notava através da prática que, apesar de trabalhar com os mesmos conceitos, por vezes, precisava descobrir outros caminhos, uma vez que trabalhava com grupos diferentes. Compreendi que o planejamento não é a finalidade, mas, sim, o meio para alcançar algo maior, que é uma experiência significativa de aprendizado.

Essa primeira fase foi marcada por diferentes tentativas de aproximação, buscando a criação de vínculos. Era necessária a construção de uma relação de parceria, onde minha figura não se confundisse com a dos outros profissionais que desempenhavam uma relação específica de poder em relação a elas e ao espaço.

\section{TROPEÇOS DE UMA ESTRANGEIRA MÍOPE}

Segundo Kershaw (apud NOGUEIRA, 2008, p.31), "'comunidade de local' é criada por uma rede de relacionamentos formados por interações face a face, numa área delimitada geograficamente". Poderíamos, então, caracterizar o CASEF como essa área e as relações que acontecem nele enquanto uma comunidade de local. No entanto, esta delimitação é imposta para as internas, sendo marcada por essa característica e seus desdo- 
bramentos. Ao compreender tal conjuntura e questionar minha passagem pelo lugar, me compreendia como estrangeira no lugar - assim como as jovens (o que merece ser melhor analisado e problematizado).

Estrangeira naquele lugar, eu queria trabalhar com o passado das meninas para a criação artístico-pedagógica, inspirada na história oral, planejava partir de questões amplas, para que as meninas não se sentissem invadidas com as proposições sobre seu passado, trazendo aquilo que quisessem compartilhar. Desta forma, esperava que elas compartilhassem através da oralidade suas memórias, que seriam material para as cenas. Ainda, outra entrada no campo da memória se daria através de exercícios de escrita, tecidos por elas. Levava, então, papéis e lápis comigo, os quais eram conferidos antes da entrada no local.

Em uma das aulas que propus uma prática de escrita, estavam presentes quatro jovens. Sentadas à volta de uma mesa, iniciei perguntando do que poderia surgir uma peça de teatro. Ao passo que elas falavam, ia escrevendo numa folha. Quando perguntei se poderíamos fazer uma peça a partir de suas histórias, elas responderam afirmativamente. Propus, então, que escrevessem uma história da sua vida, algo que tivessem presenciado ou que tivesse acontecido com elas. Percebi que elas tinham muita dificuldade para compor uma frase simples, me senti muito mal por expô-las, apesar de não ter percebido um constrangimento. Lidava, assim, com um paradoxo: apontar para o compartilhamento de histórias como um caminho para processos de emancipação e apropriação de sua própria trajetória de vida e impor a escrita para pessoas que, por múltiplas questões, não tiveram acesso à educação formal.

Pedi que elas fizessem um desenho sobre a história e depois mostrassem e contassem a história ao grupo. Esse momento me levou a compreensão de que existem outras formas de acessar as histórias de vida, outras formas de registro, corroborando para uma expansão da compreensão do ato de contar, registrar e experienciar. Dos desenhos criados, os que me chamaram mais atenção foram: o de uma menina que desenhou ela e sua irmãzinha no balanço, no qual está escrito "diversão 
de uma criança", e o de outra, que desenhou um palco, no qual ela estava presente de figurino, com uma plateia vazia, pois era um ensaio. O que despertou minha atenção em ambos foi que traziam uma projeção de futuro. Quando questionadas sobre seu passado, ali, naquela uma hora dedicada à criação, elas sonhavam com possibilidades de futuro.

Nossos encontros culminavam com um improviso. Em um deles, pedi que criassem algo a partir do que gostariam de discutir naquele espaço, inspiradas nas suas vivências, entendendo o espaço artístico como um local onde poderiam compartilhar suas inquietações.

Um dos improvisos era, basicamente, a réplica de uma novela. Achei que elas não haviam levado a sério a proposição, que estavam brincando. E, sim, elas estavam brincando, e este é um dos princípios do teatro: a partir do jogo, da brincadeira pensar o mundo. Percebi o quanto meus preconceitos sobre o conteúdo televisivo me impediam para uma maior abertura ao que elas traziam. Estavam partindo dos seus referenciais para poderem se expressar, como eu havia pedido.

Aquela situação, ainda, me levou a atentar para o fato de que elas não possuem muito contato com o mundo externo, sendo a televisão e as pessoas que vão até o CASEF suas referências externas. O meio televisivo não configura em si um problema, apenas quando se constitui como referência hegemônica, o que, infelizmente, ainda é a tônica no contexto brasileiro. Tal questão traz à tona a discussão sobre a democratização do acesso aos bens culturais.

Como querer que as jovens lançassem mão da linguagem teatral, se a maioria delas nunca foi ao teatro? Outra questão emerge, em se tratando do ensino de teatro: como trabalhar o teatro sem fruição estética? Considerando a importância da abordagem triangular ${ }^{7}$, proposta por Ana Mae Barbosa, que compreende "o fazer, o saber pensar sobre aquilo que é produzido e

7 Consiste na proposição de três abordagens que, através de sua integração, objetivam a construção de conhecimento em arte. A abordagem reflete a busca de democratização dos saberes em arte. 
a contextualização daquilo que é trabalhado" (OMAR; BARBOSA; SHULZE, 2017, p.302). Ao levar em consideração esses três pontos em relação ao trabalho com as jovens que cumprem medida socioeducativa sem possibilidade de atividade externa, a fruição não é trabalhada, sendo um referencial aproximado à televisão.

Trouxe em outro encontro estímulos para a criação de sonoridades. Em roda, pedi que criássemos uma batida base e fôssemos trazendo outros "temperos" a essa batida. Elas começaram a brincar fazendo beatbox ${ }^{8}$, "mandando" rimas. Perguntei se elas já tinham músicas e elas responderam compartilhando-as. Havia várias que tratavam do CASEF, revelando que com as músicas elas refletiam sobre seu tempo presente.

Fizemos uma breve combinação de disposição cênica, inspiradas nas batalhas de rap. Com essa atividade específica consegui despertar o prazer próprio do ato de "jogar", acessando uma das linguagens daquelas jovens ao compreender e exaltar suas referências.

Compreendi que pensar o passado é pertinente para refletirmos sobre o presente, mas se restringir apenas ao evocar dessas memórias não parece ser tão frutífero em espaços de restrição da liberdade, sobretudo, pela complexidade do passado que muitas vezes não se quer trazer à tona. Foram vários os tropeços dessa outrora dita estrangeira, de uma professora em formação. Durante o processo, meus preconceitos eram trazidos à tona e tomava consciência dos diversos discursos de "coisificação" do outro que ainda me habitavam. A compreensão de que todas éramos estrangeiras naquele lugar revelou que ali, ao compartilhar histórias, sonhos e o próprio tempo presente, estávamos buscando dar significação àquele lugar, a passagem pelo mesmo, à experiência individual e coletiva.

\section{TEMPO QUE GESTA SONHO}

Comecei, a partir do percurso, a indagar a noção de futuro como disparador para a criação dos improvisos. Futuro, segun-

8 Percussão vocal que simula sons de bateria e afins, utilizada dentro do rap; elemento da cultura Hip-Hop. 
do o Dicionário Aurélio, significa "1. Tempo que há de vir; porvir. 2. Sorte futura; destino. 3. Vindouro" (FERREIRA, 2018). A palavra abre uma fenda ao novo, possuindo forte apelo à imaginação na composição de suposições desse outro tempo. O indivíduo ao se projetar para esse outro tempo é convidado a sonhar, ampliando as perspectivas dadas no presente.

A partir de uma dinâmica de criação de fotografias coletivas, inspirada no Teatro Imagem ${ }^{9}$, de Augusto Boal ${ }^{10}$, pedi que elas criassem imagens sobre a temática de materialização dos sonhos, ou seja, de futuro em sua essência. Nesse dia a sala estava cheia de balões, remanescentes de algum evento, então, algumas meninas brincaram com eles, ampliando partes do corpo e brincando com a ideia de próteses ${ }^{11}$. A maior parte das imagens criadas, entretanto, tinha ligação com ideias de famílias. Perguntei se elas viam algo em comum, no que apontaram para a questão da família. Foi criada uma cena de véspera de Natal, a partir de uma das imagens, onde várias estavam grávidas ${ }^{12}$. O nome dado para a cena foi "Família unida". Faz-se pertinente atentar que, por mais que o tempo futuro possa acolher diversos sonhos, as jovens pareceram não buscar dar corpo a sonhos que a ficcionalização fosse mais latente. Talvez isso acon-

9 Consiste em uma das técnicas que compõem o Teatro do Oprimido, nascida no Peru, da relação com os indígenas de diferentes nações, os quais não compartilhavam da mesma língua. Assim, como aponta Boal, criador da técnica, se prescinde da palavra para que possa emergir outras formas perceptivas (1980), gerando através do campo imagético o que se quer expressar.

10 (1931-2009). Teatrólogo brasileiro, que desenvolveu as técnicas que compõem o Teatro do Oprimido, marcando profundamente o teatro, trazendo uma concepção democrática da arte, ao passo que compreendia que todos podiam se tornar atores, em um convite à ação.

11 Apesar de ser uma brincadeira, acredito que isso revele para a busca de um padrão estético que é imputado às mulheres, não sendo diferente em relação às adolescentes.

$12 \mathrm{~A}$ ideia da maternidade como experiência "obrigatória" também é imputada ao imaginário da mulher. Aponto para isso, pois acredito que uma futura pesquisa ancorada em pressupostos feministas seja profícua numa discussão desses valores com as adolescentes. 
teça pelo fato de o sonho estar vinculado ao recorte social no qual o indivíduo encontra-se, ou seja, não é que o mesmo não possa sonhar, mas, talvez, tenha passado uma vida não sendo fomentado a isso, ou, ainda, talvez o sonho esboçado por elas seja aquilo que realmente almejam, que em sua essência é uma estrutura familiar, ou, ainda, a ideia de família unida, atualmente tão distante, que configure um sonho que demanda muita ficcionalização. Minha análise revela a minha visão, ou seja, quando penso sobre o sonhar acabo revelando minha perspectiva de mundo, a qual está alicerçada na realidade em que me desenvolvi, onde alguns direitos fundamentais, que foram negados a essas jovens, me foram possíveis.

Esperava para ir embora perto do portão de entrada da instituição. No mesmo dia da improvisação compartilhada acima, um dos guardas me perguntou: "o que tu vem fazer aí com elas? Essas aí já estão perdidas!" Fiquei sem muita reação e respondi, de forma sintética, que acreditava no poder da educação. Enfaticamente respondeu: “Educação vem de casa!". Naquele momento um filme das imagens e depois da cena criada em aula passou na minha cabeça. Fiquei a me perguntar: que casa era essa que o guarda se referia, se elas tanto ansiavam por uma?

Ao buscarmos sonhar cenicamente, instiga-se a materialização dos sonhos, bem como a análise de suas motivações que, em certos casos, extrapolam o individual, sendo um desejo da ordem do coletivo que carrega consigo um panorama social a ser problematizado - como foi o caso da questão familiar, que se mostrou presente nas trajetórias de todas.

\section{TEMPO DE APROPRIAÇÃO}

Achava que a relação com o trabalho com o passado era negado pelas jovens, visto que se apresentavam reticentes à proposta. No entanto, em um dos nossos últimos encontros entendi que o que nos faltava era tempo para a construção de um espaço de escuta de minha parte em relação a elas e, decorrente, confiança. 
Começamos o encontro em roda, de mãos dadas, cantando uma cantiga popular. Elas disseram que iriam cantar uma música para mim, acabaram compartilhando várias. Ao perceber que havia outro clima naquele encontro, propus que jogássemos com a situação de uma entrevista. Dispus duas cadeiras no espaço, de frente para a plateia. Pedi duas voluntárias e uma das jovens se levantou prontamente e perguntou: "sora, posso falar da Lei Maria da Penha ${ }^{13}$ ?", assenti. Elas fizeram uma cena na qual se relatava um relacionamento abusivo, no qual se havia conseguido denunciar o agressor.

Eu não sabia se a história era real - a linha tênue entre ficção e realidade começou a ficar mais presente. Ao término da cena, a menina que havia jogado a entrevistada disse que gostaria de fazer uma cena a partir de uma história "dela mesma". Ela contou a história de sua mãe, que havia sido violentada pelo marido, que era o pai da jovem. Perguntei se poderíamos utilizar seu relato para a criação de uma cena. A menina concordou e, assim, construímos uma cena que era ora contada ora "vivida". A cena, apesar de breve, era extremamente rica, lançando mão de recursos estéticos e poéticos bem complexos como o distanciamento brechetiano ${ }^{14}$. A mãe que estava machucada, no chão, erguia a mão à menina que contava sua história, elas davam as mãos, erguendo a aluna-atriz que interpretava a mãe, que falava diretamente para a plateia sobre a importância da denúncia e do apoio. Esse encaminhamento da história, uma modificação ficcional na memória, alude ao processo de apropriação e ressignificação dela, evidenciando a compreensão que o compartilhamento da memória pode proporcionar um aprendizado, dado que se gera conhecimento a partir da análise do vivido.

13 Lei 11.340/2006. É uma lei federal brasileira, resultante de intensas mobilizações e lutas, que objetiva que sejam penalizados agressores de violências doméstica ou familiar perpetradas às mulheres.

14 Segundo Concilio (2016), é um conceito essencial do teatro de Brecht, no qual se evidencia a perspectiva histórica de algum fato, tornando-o analisável, levando a produção de conhecimento. 
Rever o passado possui potencial transformador, visto que se opera uma dupla intervenção nele: dos olhos do presente, dado que não há como voltar de maneira fidedigna ao que se passou, atualizando a memória com o tempo presente e a da ficcionalização assumida, na busca de outros significados para a memória, intensificando a autoria do sujeito nesse processo.

\section{TEMPO ENQUANTO PONTE, POTÊNCIA, PRE- SENÇA}

No contato com as aulas, repensei minha proposição inicial e entendi a importância da ficcionalização naquele contexto, operando como estratégia para se continuar sonhando. Comecei a pensar nos conceitos de passado, presente e futuro como norteadores do trabalho, dado sua articulação na operação da memória. O presente como o único momento que há e que coaduna passado e futuro. Conforme Delgado (2003, p. 18),

[...] o conceito de memória é crucial porque na memória se cruzam passado, presente e futuro; temporalidades e espacialidades; monumentalização e documentação; dimensões materiais e simbólicas; identidades e projetos. É crucial porque na memória se entrecruzam a lembrança e o esquecimento; o pessoal e o coletivo; o indivíduo e a sociedade, o público e o privado; o sagrado e o profano. Crucial porque na memória se entrelaçam registro e invenção; fidelidade e mobilidade; dado e construção; história e ficção; revelação e ocultação.

Em consonância com essa compreensão do conceito de memória, as possibilidades de trabalho se ampliam. Durante meu percurso com as jovens, tive diversas "pistas" de outras possibilidades de trabalho, mas encontrava-me fixada em um plano precedente à prática, ao encontro efetivo com as pessoas com quem iria trabalhar, com suas singularidades. Debruçar-se sobre o tempo presente como norteador para o trabalho também é voltar os olhos para si, para sua qualidade de escuta e presença, bem como sua falta de alcance. 
A noção de escuta, cara aos estudos da memória, advinda da minha busca de uma proposição distinta de dramaturgia a partir de relatos, que configurava o projeto inicial, evidenciouse necessária na relação com o passado, mas, especificamente, na articulação com o trabalho docente. Freire (1997, p. 127-128) aponta para a importância do saber escutar, atentando que "o educador que escuta aprende a difícil lição de transformar o seu discurso, às vezes necessário ao aluno, em uma fala com ele". Uma relação dialógica, assim, poderá emergir modificando as relações e suas estruturas, podendo, a partir de novas configurações, intervir no meio.

O trabalho não chegou a vir a público, em função dos feriados de final de ano, bem como da ausência das jovens nos últimos encontros e a entrada de novas participantes. Daquelas cenas e encontros, a vontade de compartilhamento do criado se esboça numa escrita-reflexão do percurso: O presente físico, daquele que vem embrulhado em papéis coloridos, marca de datas comemorativas como o Natal, é uma metáfora para o tempo presente: nele vivem o passado e futuro. O Natal enquanto imaginário da festa de família, da qual se sonha em construir. O Natal vinculado à ideia de dar à luz. Contar uma história é lançar luz. Talvez o maior presente seja a capacidade de ainda sonhar e o tempo presente, o aqui agora do teatro, pode abrir outros mundos e buscar que eles sejam possíveis. E a professora de teatro caminhar de mãos dadas a uma prática assentada no diálogo e no fomento à autonomia daquelas que lutam para serem as protagonistas das suas vidas. 


\section{REFERÊNCIAS}

BRASIL. Estatuto da Criança e do Adolescente. Disponível em: <http://www.planalto.gov.br/ccivil_03/leis/L8069.htm>. Acesso em: 20 de setembro de 2019.

. Lei Maria da Penha. Lei N. ${ }^{011.340,}$ de 7 de Agosto de 2006. Disponível: <http://www.planalto.gov.br/ccivil_03/_ ato2004-2006/2006/lei/l11340.htm> Acesso em: 20 de setembro de 2019.

CONCILIO, Vicente. Baden Baden: Modelo de ação e encenação no processo com a peça didática de Bertold Brecht. Jundiaí: Paco Editorial, 2016.

DELGADO, Lucilia de Almeida Neves. História Oral e Narrativa: tempo, memória e identidades. História Oral (Rio de Janeiro), São Paulo, v. 6, p. 9-26, 2003.

FACHINETTO, Rochele Fellini. A "casa de bonecas": um estudo de caso sobre a unidade de atendimento socioeducativo feminino no RS. Dissertação (Mestrado em Sociologia) - Instituto de Filosofia e Ciências Humanas, Universidade Federal do Rio Grande do Sul. Porto Alegre, p. 224, 2008.

FERREIRA, Aurélio Buarque de Holanda. Miniaurélio: o minidicionário da língua portuguesa. 7 ed. - Curitiba: Editora Positivo, 2008.

FREIRE, Paulo. Pedagogia da Autonomia. São Paulo: Paz e Terra, 1997.

FUNDAÇÃO de Atendimento Socioeducativo do Rio Grande do Sul. Unidades. Disponível em: <http://www.fase.rs.gov.br/wp/>. Acesso em: 20 de setembro de 2019. 
NOGUEIRA, Márcia Pompeo. Teatro em comunidades. In: FLORENTINO, Adilsom; TELLES, Narciso. Cartografias do Ensino de Teatro: das ideias às práticas. Uberlândia: UDUFO, 2008.

OMAR, Amanda C. S; BARBOSA, D. J. M. L.; SCHULZE, G. B. Abordagem Triangular e performance: reflexões e possibilidades pedagógicas na sala de aula. In: REVISTA GEARTE. v. 4, p. 295-306, 2017. 